\title{
Defined Mutant Library Sequencing (DML-Seq) for Identification of Conditional Essential Genes
} Shuai Shao ${ }^{1, ~ \#, ~ L i f a n ~ W e i ~}{ }^{1,4, ~ \#, ~ F e n g ~ X i a 1 ', ~ Y u a n x i n g ~ Z h a n g ~}{ }^{1,2,3}$, and Qiyao Wang1, 2, 3, *

${ }^{1}$ State Key Laboratory of Bioreactor Engineering, East China University of Science and Technology, Shanghai 200237, China; ${ }^{2}$ Shanghai Collaborative Innovation Center for Biomanufacturing Technology, 130 Meilong Road, Shanghai 200237, China; ${ }^{3}$ Shanghai Engineering Research Center of Maricultured Animal Vaccines, Shanghai 200237, China; ${ }^{4}$ Department of Endodontics and Operative Dentistry, Ninth People's Hospital, College of Stomatology, Shanghai Jiao Tong University School of Medicine, Shanghai, China

\#Contributed equally to this work

*For correspondence: oaiwqiyao@ecust.edu.cn

[Abstract] Transposon insertion sequencing (TIS) is an emerging technique which utilizes a massive transposon mutant library to screen specific phenotype and determine the conditional essential genetic requirements for bacterial fitness under distinct conditions combined with high-throughput parallel sequencing technology. Compared with a massive mutant library in traditional TIS, the defined mutant library sequencing (DML-Seq) has advantages as: 1) efficient mutagenesis; 2) low bottleneck effects; 3 ) avoid hotpots caused by screening; 4) can be directly used in the following experiments. Here, we described an optimized procedure of DML-Seq for fitness screen to supply classical TIS using the marine pathogenic bacterium Edwardsiella piscicida as an example.

Keywords: TIS, DML-seq, Defined mutant library, Conditional essential genes

[Background] Transposon insertion mutagenesis coupled with next-generation sequencing (NGS) has been proven to be a powerful method to investigate gene function under a multitude of conditions (Chao et al., 2016; Price et al., 2018). In general, TIS analysis consists of the massive parallel sequencing of transposon insertion sites and statistical analysis of the abundance of the insertion events.

TIS-based screens can provide high-resolution maps of the fitness contributions of individual loci and domains based on the bacterial fitness of highly saturated transposon mutant libraries under a multitude of conditions (Chao et al., 2016). The insertion frequency at each locus or the relative abundance of corresponding mutants is generally inversely correlated with the locus's contribution to fitness following the imposition of a selective pressure, such as that imposed by hosts and antibiotics (Chao et al., 2016). The principles of this methodology underlie a variety of related approaches, including TIS, transposon sequencing (TnSeq), insertion sequencing (INSeq), transposon-directed insertion site sequencing (TraDIS), high-throughput insertion tracking by deep sequencing (HITS), and transposon insertion site sequencing (TIS-Seq) (Gawronski et al., 2009; Langridge et al., 2009; Chao et al., 2016; Veeranagouda et al., 2017; Price et al., 2018). These approaches are revolutionizing microbiological studies by facilitating unprecedented and deep genome-wide explorations of a wide range of bacterial species. 
With the aim to generate highly saturated mutant libraries for further analysis, the insertion events caused by transposon should be unbiased and the transposon will be delivered into recipient cells several times. However, this will lead to a large amount of nonsense mutation and the complexity of mutant libraries may cause bottleneck effect during the following screens. Compared with this, the defined mutant libraries containing mutants with a single insertion at a known genomic location will be more useful and facilitated (Fu et al., 2013; Abel et al., 2015). The first human pathogenic bacterium defined mutant library for Pseudomonas aeruginosa was constructed in 2003. Subsequently, many defined mutant libraries of human pathogens were also generated, such as a library of Francisella tularensis in 2007, Vibrio cholera in 2008, Burkholderia thailandensis in 2013, Chlamydia and Mycobacterium in 2015 (Jacobs et al., 2003; Gallagher et al., 2007 and 2013; Cameron et al., 2008; Kokes et al., 2015). With these defined mutant libraries, a myriad of important researches were completed, such as the identification of ciprofloxacin resistome from $P$. aeruginosa library, a novel T6SS regulator TsrA from $V$. cholera library, and the exploration of functional genomics with Desulfovibrio alaskensis G20 library (Breidenstein et al., 2008; Zheng et al., 2008 and 2010; Kuehl et al., 2014). Hence, such defined libraries may serve as valuable resources because they often consist of collections of insertion mutants in almost all non-essential loci for an organism of interest and have drawn more attention to the exploration of functional genomics of microbe.

In order to optimize TIS approach, we developed the DML-seq method which adopts the mixed defined mutant libraries for conditional essential fitness screenings (Figure 1) (Wei et al., 2019a and 2019b). Compared with massive mutant library in traditional TIS, the DML library has advantages as: 1) insertions within the $80 \%$ of the ORF to ensure the effective mutagenesis; 2 ) low complexity and few isogenes to ensure low bottleneck effects; 3) the mixture of an equal amount of individual mutants to avoid hotpots caused by screening; 4) can be directly used in the following experiments.

Compared to human pathogenic bacterium, the pathogenesis of marine pathogenic bacterium is poorly understood. In our model organism Edwardsiella piscicida, which causes Edwardsiellosis in farmed fish and leads to severe economic losses in aquaculture worldwide (Leung et al., 2019), DMLseq has been employed to identify conditional essential genes as well as those crucial for survival in different environments (Wei et al., 2019b), colonization and infection in host cells (Wei et al., 2019a). Briefly, we constructed MKGR, a derivative of Himar1 mariner transposon based on MAR2XT7 (Liberati et al., 2006), to generate a library of random transposon insertion mutants of E. piscicida EIB202 (Table 1). In total, 2,806 genes were disrupted out of the 3,599 predicted genes with an average of 5.04-fold coverage on E. piscicida chromosome. After that, 5 non-redundant subset libraries were created manually. The $1^{\text {st }}$ and $2^{\text {nd }}$ subset libraries contained a single mutant for each disrupted ORF in the parental library and they were paralleled for each other. The $3^{\text {rd }}$ subset library contains transcriptional fusion mutants to eliminate the location effect on transcription. The $4^{\text {th }}$ subset library is an intergenic library and the $5^{\text {th }}$ library was a composited library, which was generated by mixing the $1^{\text {st }}, 2^{\text {nd }}, 4^{\text {th }}$ subset libraries into a pool.

Here, we will focus on the specific steps for DML-seq because the excellent protocols deTAILing TIS analyses are reviewed and available elsewhere (Chao et al., 2016; Yamaichi et al., 2017). In principle, 
the procedure described here can be applied to conditional essential screens and facilitate the exploration of functional genomics of microbe.

Table 1. The statistic values of defined mutant library of E. piscicida EIB202

\begin{tabular}{ll}
\hline Data set & Number \\
\hline Mapped insertion sites & 24470 \\
Mutants mapped & 20668 \\
Ambiguous insertions & 4124 \\
Insertions inside ORFs & 18128 \\
Insertions between ORFs & 6342 \\
Insertions inside 5-85\% ORFs & 14028 \\
Insertions outside 5-85\% ORFs & 4100 \\
Transcription Fusion & 12295 \\
Transposon with - frame insertions & 12383 \\
Transposon with + frame insertions & 12087 \\
Annotated ORFs on ElB202 & 3599 \\
ORFs disrupted & 2806 \\
ORFs never disrupted & 793 \\
Average hits per annotated ORF & 5.04 \\
Predicted essential genes & 464 \\
Conditional essential genes in $16{ }^{\circ} \mathrm{C}$ sea water & 158 \\
Conditional essential genes in $28{ }^{\circ} \mathrm{C}$ sea water & 75 \\
Conditional essential genes in DMEM medium & 52 \\
Conditional essential genes in J774A.1 & 67 \\
Conditional essential genes in turbot & 258 \\
\hline
\end{tabular}


$\mathbf{A}$

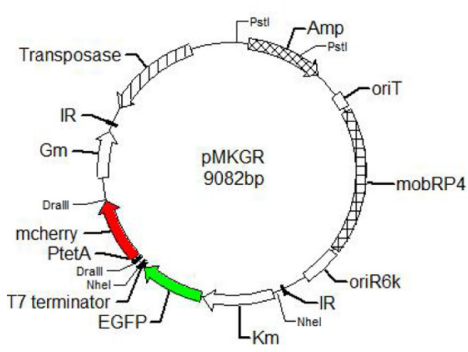

C

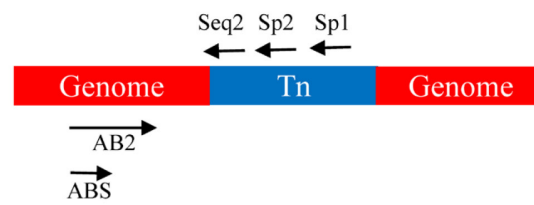

D

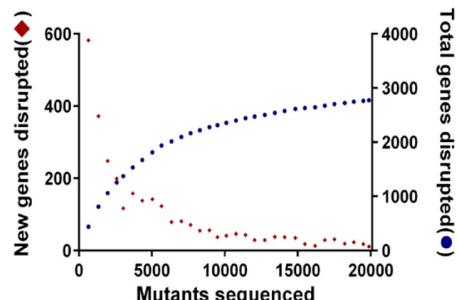

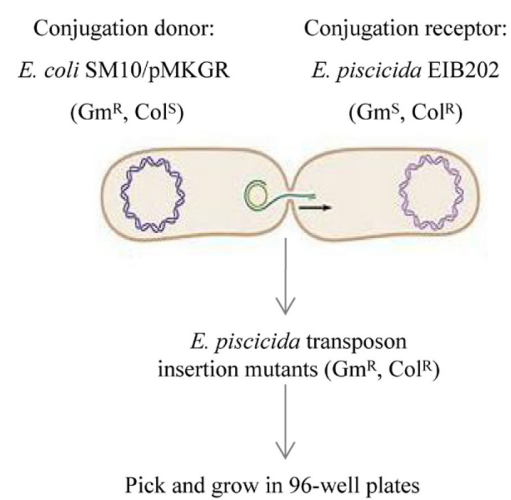

(master library)
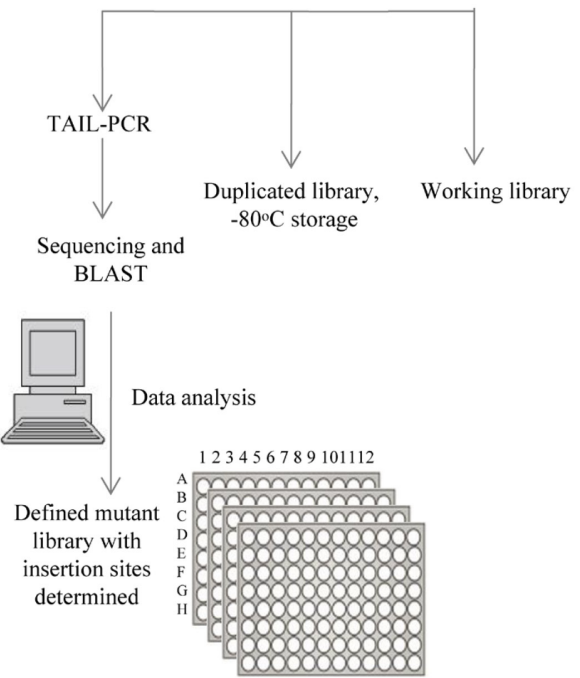

Figure 1. A defined transposon mutant library construction. A. pMKGR, a derivative of Himar1 mariner transposon, was constructed to build the defined transposon mutant library of E. piscicida EIB202. B. Work flow of a defined mutant library construction. E. coli SM10 is used as a donor for conjugation with recipient strain E. piscicida EIB202. Conjugation is processed between EIB202 and SM10 on LB plates for $3 \mathrm{~h}$ at $30^{\circ} \mathrm{C}$. Later, conjugators are separated on LB plates containing $20 \mu \mathrm{g} / \mathrm{ml}$ polymyxin and $15 \mu \mathrm{g} / \mathrm{ml}$ gentamicin. After $24 \mathrm{~h}$ of incubation at $30{ }^{\circ} \mathrm{C}$, monoclonal will be picked into 96 -well plates and incubated at $30{ }^{\circ} \mathrm{C}$ for about $16 \mathrm{~h}$. Before storing at $-80{ }^{\circ} \mathrm{C}$, glycerol was added into every well and mix to make the final $20 \%$ glycerol concentration to preserve strains. C. Schematic of TAIL-PCR amplification used for determination of the $\mathrm{Tn}$ insertion loci on the genome. The pair of primer Sp1/AB2 is used for the first round of PCR and another pair of primer Sp2/ABS is used for the second round of PCR. Finally, primer Seq2 is used for sequencing of the amplified PCR products. D. The number of new disrupted genes increased linearly with new mutants and the number of genes hit approached a plateau. 


\section{Materials and Reagents}

A. Handling Bacteria

1. Large square Petri dish $\left(500 \mathrm{~cm}^{2}\right)$ (Thermo Fisher Scientific, catalog number: R80115TS)

2. Cellulose filter membrane $(0.45 \mu \mathrm{m}$ pore size, Merck Millipore)

3. Eppendorf tube (Axygen, catalog number: MCT-150-C)

4. PCR tube (Axygen, catalog number: PCR-02-A)

5. Corning $50 \mathrm{ml}$ centrifuge tube (Merck, catalog number: CLS430828-500EA)

6. 96-Well Deep Well Plates (Thermo Fisher Scientific, catalog number: A43075)

7. Cryotube (Thermo Fisher Scientific, catalog number: 5000-1020)

8. Wild type E. piscicida ElB202 (ColR); "recipient" cells

9. E. coli SM10 גpir harboring pMKGR for delivering $\mathrm{Tn}$ via conjugation $\left(\mathrm{Amp}^{\mathrm{R}}, \mathrm{Km}^{\mathrm{R}}\right)$; "donor" cells (see Note 1)

10. Luria-Bertani (Miller's LB Broth Base, Thermo Fisher Scientific, catalog number: 12795027) and agar media (Merck, catalog number: 05040)

11. Colistin (Col, $20 \mathrm{mg} / \mathrm{ml}, \mathrm{BBI}$ )

12. Ampicillin (Amp, $100 \mathrm{mg} / \mathrm{ml}, \mathrm{BBI}$ )

13. Gentamicin ( $\mathrm{Gm}, 15 \mathrm{mg} / \mathrm{ml}, \mathrm{BBI})$

14. Glycerol (Titan, catalog number: 56-81-5)

B. Thermal Asymmetric Interlaced PCR (TAIL-PCR)

1. Tiangen $2 \times$ Taq PCR MasterMix (TIANGEN BIOTECH, catalog number: KT205-02)

2. Nuclease-free water $\mathrm{H}_{2} \mathrm{O}$ (QIAGEN, catalog number: 129114)

C. Genomic DNA (gDNA) Purification

1. $0.5 \mathrm{ml}$ individual tubes (Thermo Fisher Scientific, catalog number: $A B 0350$ )

2. Tiangen gDNA extraction kit (TIANGEN BIOTECH, catalog number: DP302-02)

3. $100 \%$ ethanol (Titan, catalog number: $64-17-5$ )

D. Library Construction

1. Qiagen Gel purification kit (QIAGEN, catalog number: 28104)

2. VAHTS HiFi Amplification Mix (Vazyme Biotech, catalog number: 616-01/02)

3. Agarose (Thermo Fisher Scientific, catalog number: 16500500) and Electrophoresis apparatus (BIO-RAD, catalog number: 1704489EDU)

4. Qubit ${ }^{\mathrm{TM}}$ dsDNA HS Assay kit (Invitrogen, catalog number: Q32851)

E. Oligo DNAs (See Note 2) (HPLC purified, BGI)

1. "EIB202-F": 5'-TCATCGCACATACAGAATAAACGCC-3'

2. "EIB202-R": 5'-CCGTAACATTTCTTACAACACTGCG-3' 
3. "pMKGR-F": 5'-AGGTGATGCTACATACGGAAAG-3'

4. "pMKGR-R": 5'-AGCGCATGAACTCCTTGATG-3'

5. "Tn-F": 5'-AAAAGTCCGCTGGCAAAG-3'

6. “Tn-R": 5'-CCCTTCAAGAGCGATACAAC-3'

7. "Sp1-F": 5'-GCTCCGTAGTAAGACATTCATCGCG-3'

8. "Sp2-F": 5'-GCTTACGTTCTGCCCAAGTTTGAG-3'

9. "ABS-R": 5'-GGCCACGCGTCGACTAGTAC-3'

10. "AB2-R": 5'-GGCCACGCGTCGACTAGTACNNNNNNNNNNCCTGG-3'

11. "Seq2-F": 5'-CAATTCGTTCAAGCCGAGATCG-3'

12. "AD_fork truncated NH2": 5'- TACCACGACCA-3'

13. "AD_Index Fork R": 5'- GTGACTGGAGTTCAGACGTGTGCTCTTCCGATCTATGGTCGTGGT3'

14. "1st_seq-out-psc189": 5'- ACTCTGGGGTACGCGTCTAG-3'

15. "1st_PCR_Index 'R' primer": 5'-GTGACTGGAGTTCAGACGTGTG-3'

16. "P5 spacer primers": equimolar mixture of the following 6 oligos:

5

AATGATACGGCGACCACCGAGATCTACACTCTTTCCCTACACGACGCTCTTCCGATCTGAC TTATCAGCCAACCTGT-3'

5

AATGATACGGCGACCACCGAGATCTACACTCTTTCCCTACACGACGCTCTTCCGATCTCGA CTTATCAGCCAACCTGT-3'

5 -

AATGATACGGCGACCACCGAGATCTACACTCTTTCCCTACACGACGCTCTTCCGATCTATG ACTTATCAGCCAACCTGT-3'

5

AATGATACGGCGACCACCGAGATCTACACTCTTTCCCTACACGACGCTCTTCCGATCTTGT CGACTTATCAGCCAACCTGT-3'

5

AATGATACGGCGACCACCGAGATCTACACTCTTTCCCTACACGACGCTCTTCCGATCTTCG ACGACTTATCAGCCAACCTGT-3'

5

AATGATACGGCGACCACCGAGATCTACACTCTTTCCCTACACGACGCTCTTCCGATCTGCA GCGACGACTTATCAGCCAACCTGT-3'

17. "P7 barcode primers"

CAAGCAGAAGACGGCATACGAGATNNNNNNGTGACTGGAGTTCAGACGTGTGCTCTTCC GATC (vary from sample to sample) 


\section{Equipment}

1. Multichannel pipette (Thermo Fisher Scientific)

2. High speed centrifuge (Eppendorf, model: $5415 \mathrm{R}$ )

3. Thermal cycler (EASTWIN, model: ETC811)

4. Water bath (Thermo Fisher Scientific, catalog number: TSGP02)

5. High speed centrifuge (Eppendorf, model: 5415R)

6. Bath sonicator (Diagenode, catalog number: B01020001)

7. Thermal cycler (EASTWIN, catalog number: ETC811)

8. VAHTS Universal End preparation Module for Illumina (Vazyme Biotech, catalog number: N20301)

9. VAHTS Universal Adapter Ligation Module for Illumina (Vazyme Biotech, catalog number: N204-01)

10. Qubit ${ }^{\mathrm{TM}} 4$ Fluorometer (Invitrogen, catalog number: Q33238), or equivalent fluorescent-based DNA quantification apparatus

\section{Procedure}

A. Parental Library Construction

1. Inoculate "donor" (in LB broth with Amp, $100 \mu \mathrm{g} / \mathrm{ml}$ ) and "recipient" cells (in LB broth with Col, $20 \mu \mathrm{g} / \mathrm{ml}$ ) at $37^{\circ} \mathrm{C}$ with shaking and culture overnight.

2. Prepare LB agar plate(s) without antibiotics. Let them dry well and place $0.45 \mu \mathrm{m}$ membrane filters on top of the plates (four membranes can be applied to each plate) (see Note 3).

3. Passage E. piscicida, $2 \mathrm{ml}$ in $50 \mathrm{ml}(4 \%)$, add $\mathrm{CaCl}_{2}$ to $50 \mathrm{mM}(500 \mu \mathrm{l}, 10 \mathrm{M})$, Rotate $200 \mathrm{rpm}$ at $30{ }^{\circ} \mathrm{C}$, the $\mathrm{OD}_{600}$ will reach $\sim 0.6-0.8$ after 1 h 15 min culture (see Note 4).

4. Measure the $\mathrm{OD}_{600}$ of all bacteria, which are expected to be 0.8 , for SM10 and E. piscicida, respectively.

5. Move the culture into $50 \mathrm{ml}$ corning tubes, spin $5,000 \times g$ at $10{ }^{\circ} \mathrm{C}$ for $5 \mathrm{~min}$, then wash with 10 $\mathrm{ml} L B$ and spin $5,000 \times g$ for $10 \mathrm{~min}$.

6. Resuspend in LB with the following volume to reach final $\mathrm{OD}_{600}=4$.

7. Mix equal volume of SM10 and E. piscicida in an Eppendorf tube, and spot $4^{*} 80 \mu \mathrm{l}$ on the filter prepared in Step A2. Let drop adsorb into the agar and dry.

8. Place these plates into a $30^{\circ} \mathrm{C}$ incubator with care not to let the cell suspension spill outside the membrane (do not flip the plate).

9. After $3 \mathrm{~h}$ of incubation, remove the filter into a $50-\mathrm{ml}$ centrifuge tube by forceps. Resuspend cells from filters in $1 \mathrm{ml}$ of LB broth by pipetting up/down and vortexing.

10. Make serial dilutions of resuspended cells and plate $100 \mu \mathrm{l}$ of $1: 1,1: 10$, and 1:100 dilutions onto LB agar plates containing Col and $\mathrm{Gm}$ (to provide an estimate of transposon insertion efficiency, 
as the actual library plates can become too crowded to pick colonies). Incubate overnight at $30^{\circ} \mathrm{C}$.

11. Examine $\sim 100 \mathrm{Col}^{R} \mathrm{Gm}^{\mathrm{R}}$ colonies by colony PCR with 3 pairs of universal primers ElB202-F/R, pMKGR-F/R, and Tn-F/R (see Note 5).

12. Pick monoclonal into 96 deep well plates, rotate $200 \mathrm{rpm}$ at $30^{\circ} \mathrm{C}$ overnight.

13. Mix $900 \mu \mathrm{l}$ of cells with $300 \mu \mathrm{l}$ of $80 \%$ glycerol into cryotube to store a recoverable library at $80^{\circ} \mathrm{C}$.

B. Thermal Asymmetric Interlaced PCR (TAIL-PCR)

1. For each monoclonal, prepare the first reaction system in a PCR tube:

$0.5 \mu \mathrm{l}$ bacterial culture (from Subheading 3.1).

$1 \mu \mathrm{l} 10 \mu \mathrm{M}$ "Sp1-F".

$1 \mu \mathrm{l} 10 \mu \mathrm{M}$ "AB2-R".

$10 \mu \mathrm{l}$ Tiangen $2 \times$ Taq PCR MasterMix.

Add $\mathrm{H}_{2} \mathrm{O}$ to $20 \mu \mathrm{l}$.

2. Run on the PCR Thermo cycler under the program.

$1=94{ }^{\circ} \mathrm{C}$ for $4 \mathrm{~min}$.

$2=94{ }^{\circ} \mathrm{C}$ for $30 \mathrm{~s}$.

$3=42{ }^{\circ} \mathrm{C}$ for $30 \mathrm{~s}$.

[option] $-1{ }^{\circ} \mathrm{C}$ per cycle.

$4=72{ }^{\circ} \mathrm{C}$ for $3 \mathrm{~min}$.

$5=$ go to 2,6 times.

$6=94{ }^{\circ} \mathrm{C}$ for $30 \mathrm{~s}$.

$7=58^{\circ} \mathrm{C}$ for $30 \mathrm{~s}$.

$8=72{ }^{\circ} \mathrm{C}$ for $1 \mathrm{~min}$.

$9=$ go to 6,25 times.

$10=72{ }^{\circ} \mathrm{C}$ for $3 \mathrm{~min}$.

3. Dilute the PCR product ten-fold, prepare the second reaction system in a PCR tube:

$1 \mu$ l Dilute PCR products.

$2 \mu \mathrm{l} 10 \mu \mathrm{M}$ "Sp2-F".

$2 \mu \mathrm{l} 10 \mu \mathrm{M}$ "ABS-R".

$25 \mu$ l Tiangen 2× Taq PCR MasterMix.

Add $\mathrm{H}_{2} \mathrm{O}$ to $50 \mu \mathrm{l}$.

4. Run on the PCR Thermo cycler under the program.

$1=94{ }^{\circ} \mathrm{C}$ for $3 \mathrm{~min}$.

$2=94{ }^{\circ} \mathrm{C}$ for $30 \mathrm{~s}$.

$3=64{ }^{\circ} \mathrm{C}$ for $30 \mathrm{~s}$.

$4=72{ }^{\circ} \mathrm{C}$ for $1 \mathrm{~min}$.

$5=$ go to 2,30 times. 
$6=72^{\circ} \mathrm{C}$ for $3 \mathrm{~min}$.

5. Collect the PCR product and sequence with primer "Seq2".

C. Non-redundant Subset Library Construction (see Note 6, E. piscicida EIB202 used as an example)

1. Sequence results are mapped to recipient EIB202 genome.

2. Saturation curve is drawn to ensure the saturation of the library.

3. According to identified insertion sites, non-redundant subset libraries were generated manually to facilitate a genome-wide screen.

4. According to different experimental purposes, non-redundant subset libraries would be used for the screen.

D. gDNA Extraction

Use commercial gDNA extraction kit, refer to relevant protocol.

E. gDNA Shearing by Sonication

1. Dilute gDNA in fresh $0.5 \mathrm{ml}$ individual tubes to a final concentration of $50 \mathrm{ng} / \mu \mathrm{l}$ in $100 \mu \mathrm{l} \mathrm{H}_{2} \mathrm{O}$.

2. Sonicate DNA to yield fragments: 30 s ON/ 90s OFF, for 12 cycles.

3. Run a sample $(5 \mu \mathrm{l})$ of the digest on an agarose gel $(2 \%)$. Most of the DNA should fall in the range of 200-500 bp, which will be fine for downstream ligations and PCR.

F. End Repair and A-TAILing

1. Prepare the reaction in a PCR tube:

VAHTS Turbo End Prep Enzyme Mix: $3.0 \mu$ l.

VAHTS Turbo End Prep Reaction Buffer (10x): $6.5 \mu$ l.

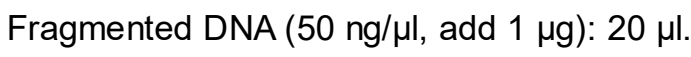

Add $\mathrm{H}_{2} \mathrm{O}$ to $65.0 \mu \mathrm{l}$.

2. Carry out PCR using the following cycling conditions.

$1=20^{\circ} \mathrm{C}$ for $30 \mathrm{~min}$.

$2=65^{\circ} \mathrm{C}$ for $30 \mathrm{~min}$.

G. Adapter Ligation

1. Prepare the following adapter mixture in a PCR tube.

$5 \mu \mathrm{l} 100 \mu \mathrm{M}$ "AD_fork truncated NH2".

$5 \mu \mathrm{l} 100 \mu \mathrm{M}$ "AD_Index Fork R".

$0.4 \mu \mathrm{l} 2 \mathrm{mM} \mathrm{MgCl} 2$.

2. Run on the PCR Thermo cycler under the program.

$1=95^{\circ} \mathrm{C}$ for $4 \mathrm{~min}$.

$2=95^{\circ} \mathrm{C}$ for $1 \mathrm{~min}$.

[option] $-1{ }^{\circ} \mathrm{C}$ per cycle. 
$3=$ go to 2,75 times.

$4=$ End.

3. Dilute to half concentration: Add the same volume of $\mathrm{H}_{2} \mathrm{O}$.

4. Prepare the following ligation reaction in a PCR tube.

A-TAlLed DNA (from above Subheading 3.5): $65 \mu \mathrm{l}$.

VAHTS Turbo T4 DNA Ligase: $2.0 \mu$.

VAHTS Turbo Ligation Enhancer: $30.5 \mu \mathrm{l}$.

Adapter for Tn-seq (from above Subheading 3.6, step 2): $2.5 \mu \mathrm{l}$.

Add $\mathrm{H}_{2} \mathrm{O}$ to $100 \mu \mathrm{l}$.

5. Incubate the reaction at $20^{\circ} \mathrm{C}$ for $30 \mathrm{~min}$.

6. Column-purify DNA, elute with $35 \mu$ l pre-warmed $\mathrm{H}_{2} \mathrm{O}$.

H. Amplification of Tn-associated gDNA

1. Prepare the following PCR reaction in an Eppendorf tube.

$50 \mu \mathrm{l}$ VAHTS HiFi Amplification Mix.

200 ng Ligated DNA (from Subheading 3.6).

$5 \mu \mathrm{l} 10 \mu \mathrm{M}$ "1st_seq-out-psc189 primer".

$5 \mu \mathrm{l} 10 \mu \mathrm{M}$ “1st_PCR_Index 'R' primer”.

Add $\mathrm{H}_{2} \mathrm{O}$ to $100 \mu \mathrm{l}$.

2. Aliquot into 2 PCR tubes ( $50 \mu \mathrm{l}$ each) and carry out PCR using the following cycling conditions.

$1=98^{\circ} \mathrm{C}$ for $30 \mathrm{~s}$.

$2=98^{\circ} \mathrm{C}$ for $10 \mathrm{~s}$.

$3=53^{\circ} \mathrm{C}$ for $30 \mathrm{~s}$.

$4=72{ }^{\circ} \mathrm{C}$ for $30 \mathrm{~s}$.

$5=$ go to 2,29 times in all.

$6=72{ }^{\circ} \mathrm{C}$ for $5 \mathrm{~min}$.

3. Pool the $2 \mathrm{PCR}$ reactions and then column-purify the PCR products, elute with $35 \mu$ pre-warmed $\mathrm{H}_{2} \mathrm{O}$.

I. Second PCR to Add barcodes, Illumina Attachment (P5, P7) and Variability Sequences

1. Prepare the following PCR reaction in an Eppendorf tube.

300 ng purified PCR product (from Subheading 3.7).

$75 \mu \mathrm{l}$ VAHTS HiFi Amplification Mix.

$7.5 \mu \mathrm{l} 10 \mu \mathrm{M}$ "P5 spacer primers".

$7.5 \mu \mathrm{l} 10 \mu \mathrm{M}$ P7 Index barcode (should vary sample by sample).

Add $\mathrm{H}_{2} \mathrm{O}$ to $150 \mu \mathrm{l}$.

2. Aliquot into 3 PCR Tubes ( $50 \mu \mathrm{l}$ each) and carry out PCR using the following cycling conditions.

$1=98^{\circ} \mathrm{C}$ for $30 \mathrm{~s}$.

$2=98^{\circ} \mathrm{C}$ for $10 \mathrm{~s}$. 
$3=55^{\circ} \mathrm{C}$ for $30 \mathrm{~s}$.

$4=72{ }^{\circ} \mathrm{C}$ for $30 \mathrm{~s}$.

$5=$ go to 2,17 times total.

$6=72{ }^{\circ} \mathrm{C}$ for $7 \mathrm{~min}$.

3. Pool the 3 PCR reactions and then column-purify the PCR products, elute with $35 \mu$ pre-warmed $\mathrm{H}_{2} \mathrm{O}$.

J. Size Selection

1. Run all the purified PCR products (from Subheading 3.8 ) on a $2 \%$ agarose gel in $0.5 \times \mathrm{TAE}$ buffer.

2. Size select by cutting out the smear between 200 and $500 \mathrm{bp}$. Make sure not to include the visible head-to-head primer dimers around $200 \mathrm{bp}$.

3. Column-purify DNA using a standard gel extraction procedure, elute with $50 \mu \mathrm{l}$ pre-warmed $\mathrm{H}_{2} \mathrm{O}$.

4. Quantify the DNA concentration by Qubit. Now the DNA is ready to be run on an Illumina sequencer.

K. Conditional Essential Genes analysis

The transposition loci and the abundance of the insertions are determined using the EL-ARTIST pipeline (Chao et al., 2013). Based on the neutral base pair model, a random distribution of transposon insertions, a library containing $n$ mutants, and the total genes number on the genome is $k$, the number of genes uncovered by transposon is $\mathrm{N}$. The probability of gene $\mathrm{j}$ getting insertion $p_{\mathrm{j}}$, the uncovered genes number by transposon is $\mathrm{N}_{\mathrm{t}}=\sum_{j=1}^{k}\left(1-p_{j}\right)^{n}$. The essential genes number is set as $k 1$. As neutral base pair model, the probability of essential genes uncovered $\mathrm{N}_{\mathrm{e}}=$ $\sum_{j=1}^{k 1}\left(1-p_{j}\right)^{n}$ and the predicted essential genes number $k 1=\mathrm{N}-\mathrm{N}_{\mathrm{t}}+\mathrm{N}_{\mathrm{e}}$.

\section{Notes}

1. PMKGR was constructed based on Himar1 mariner transposon. The promoterless kanamycin resistance $\left(\mathrm{Kan}^{r}\right)$ cassette and gene egfp with ribosomal binding site (RBS) were amplified. The RBS sequence used in this study was "AAGGAGG", which originated from the E. piscicida 16S rRNA 3' terminal conserved sequence "CCUCCUU". A triple terminal sites "TGACTAGCTAA" and 48-bp T7 terminator sequence were introduced into pMKGR. The constructed pMKGR was transformed into E. coli SM10 and validated by PCR and sequencing.

2. The pMKGR, a derivative of Himar1 mariner transposon and strain E. piscicida ElB202 are used as examples in this protocol; for different transposons and strains, all primer sequences need to be modified accordingly.

3. The prepared membranes should be as many as conjugation reactions. With more and more picked colonies for sequencing, the number of disrupted genes is increasing and the increasing rate becomes horizontal gradually and reaches a plateau in Step C2. It means that plenty of 
mutagenesis has already been generated and collected mutants are able to assemble a comprehensive and saturated library.

4. The optimal growth temperature of E.piscicida EIB202 is $30^{\circ} \mathrm{C}$. The following incubation temperature needs to be modified according to different recipient strains.

5. When antibiotics are used as selective markers, there is a small chance to observe colonies that are not truly resistant and can grow in the presence of antibiotics even without containing a transposon insertion (phenotypic resistance). To ensure successful transposition, it is suggested to randomly restreak $\sim 100$ colonies on fresh plates and perform colony PCR with 3 pairs of universal primers which are designed for transposon, its vector plasmid and "recipient" cells. For colony PCR, 1) Pick a single colony with a sterile flat toothpick or pipette tip and swirl in sterile water. 2) Lyse the bacteria to release DNA by either simply boiling the sample before use or directly adding a small volume of the sample to the PCR reaction. The bacteria will be lysed at the initial heating step of the conventional PCR procedure. 3) The cycling conditions are: $98{ }^{\circ} \mathrm{C}, 1 \mathrm{~min}$; followed by 30 cycles of $98{ }^{\circ} \mathrm{C}, 5 \mathrm{~s} ; 55^{\circ} \mathrm{C}, 5 \mathrm{~s}$; and $72{ }^{\circ} \mathrm{C}, 40 \mathrm{~s}$. 4) The size of PCR products is determined by electrophoresis and then PCR products are verified with Sanger Sequencing.

6. Five subset libraries were separated from the parental library. The $1^{\text {st }}$ and parallel $2^{\text {nd }}$ subset libraries include a single mutant for each ORF, respectively and insertion sites at 0.4-0.6 percentage within each ORF 5'-3' end were given priority. Once the ORF contains only one insertion site, these mutants were selected prior into $1^{\text {st }}$ subset library. The $3^{\text {rd }}$ subset library is a transcriptional fusion library in which each mutant carries the same orientation of MKGR with local ORF and the priority was given to insertion sites near the 5' end of each ORF. Similar to the $1^{\text {st }}$ subset library criteria, the $4^{\text {th }}$ library was generated and includes no more than two mutants for each intergenic region. The $5^{\text {th }}$ compound library is the mixture of all the mutants from the $1^{\text {st }}, 2^{\text {nd }}$ and $4^{\text {th }}$ subset libraries and takes $2 \times 10^{7} \mathrm{CFU}$ for each corresponding mutant.

\section{Acknowledgments}

The described protocol is adapted from Wei et al., 2019. This work was supported by grants from the National Natural Science Foundation of China (32002436 to S.S., 82001033 to L.W.), National Key Research and Development Program of China (2018YFD0900504 to Q.W.), Shanghai Sailing Program (20YF1411100), China Postdoctoral Science Foundation (2020M671034), Ministry of Agriculture of China (CARS-47), and the Science and Technology Commission of Shanghai Municipality (17391902000).

\section{Competing interests}

There are no conflicts of interest or competing interest. 


\section{References}

1. Abel, S., Abel zur Wiesch, P., Chang, H. H., Davis, B. M., Lipsitch, M. and Waldor, M. K. (2015). Sequence tag-based analysis of microbial population dynamics. Nat Methods 12(3): 223-226.

2. Breidenstein, E. B., Khaira, B. K., Wiegand, I., Overhage, J. and Hancock, R. E. (2008). Complex ciprofloxacin resistome revealed by screening a Pseudomonas aeruginosa mutant library for altered susceptibility. Antimicrob Agents Chemother 52(12): 4486-4491.

3. Cameron, D. E., Urbach, J. M. and Mekalanos, J. J. (2008). A defined transposon mutant library and its use in identifying motility genes in Vibrio cholerae. Proc Natl Acad Sci U S A 105: 87368741.

4. Chao, M. C., Abel, S., Davis, B. M. and Waldor, M. K. (2016). The design and analysis of transposon insertion sequencing experiments. Nat Rev Microbiol 14: 119-128.

5. Chao, M. C., Pritchard, J. R., Zhang, Y. J., Rubin, E. J., Livny, J., Davis, B. M. and Waldor, M. K. (2013). High-resolution definition of the Vibrio cholerae essential gene set with hidden Markov model-based analyses of transposon-insertion sequencing data. Nucleic Acids Res 41(19): 9033-9048.

6. Fu, Y., Waldor, M. K. and Mekalanos, J. J. (2013). Tn-Seq analysis of Vibrio cholerae intestinal colonization reveals a role for T6SS-mediated antibacterial activity in the host. Cell Host Microbe 14(6): 652-663.

7. Gallagher, L. A., Ramage, E., Jacobs, M. A., Kaul, R., Brittnacher, M. and Manoil, C. (2007). $\underline{A}$ comprehensive transposon mutant library of Francisella novicida, a bioweapon surrogate. Proc Natl Acad Sci U S A 104(3): 1009-1014.

8. Gallagher, L. A., Ramage, E., Patrapuvich, R., Weiss, E., Brittnacher, M. and Manoil, C. (2013). Sequence-defined transposon mutant library of Burkholderia thailandensis. mBio 4(6): e0060400613

9. Gawronski, J. D., Wong, S. M., Giannoukos, G., Ward, D. V. and Akerley, B. J. (2009). Tracking insertion mutants within libraries by deep sequencing and a genome-wide screen for Haemophilus genes required in the lung. Proc Natl Acad Sci U S A 106:16422-16427.

10. Jacobs, M. A., Alwood, A., Thaipisuttikul, I., Spencer, D., Haugen, E., Ernst, S., Will, O., Kaul, R., Raymond, C., Levy, R., Chun-Rong, L., Guenthner, D., Bovee, D., Olson, M. V. and Manoil, C. (2003). Comprehensive transposon mutant library of Pseudomonas aeruginosa. Proc Natl Acad Sci U S A 100(24): 14339-14344.

11. Kokes, M., Dunn, J. D., Granek, J. A., Nguyen, B. D., Barker, J. R., Valdivia, R. H. and Bastidas, R. J. (2015). Integrating chemical mutagenesis and whole-genome sequencing as a platform for forward and reverse genetic analysis of Chlamydia. Cell Host Microbe 17: 716-725.

12. Kuehl, J. V., Price, M. N., Ray, J., Wetmore, K. M., Esquivel, Z., Kazakov, A. E., Nguyen, M., Kuehn, R., Davis, R. W., Hazen, T. C., Arkin, A. P. and Deutschbauer, A. (2014). Functional genomics with a comprehensive library of transposon mutants for the sulfate-reducing bacterium Desulfovibrio alaskensis G20. mBio 5(3): e01041-01014. 
13. Langridge, G. C., Phan, M. D., Turner, D. J., Perkins, T. T., Parts, L., Haase, J., Charles, I., Maskell, D. J., Peters, S. E., Dougan, G., Wain, J., Parkhill, J. and Turner, A. K. (2009). Simultaneous assay of every Salmonella Typhi gene using one million transposon mutants. Genome Res 19(12): 2308-2316.

14. Leung, K. Y., Wang, Q., Yang, Z. and Siame, B. A. (2019). Edwardsiella piscicida: A versatile emerging pathogen of fish. Virulence 10(1): 555-567.

15. Liberati, N. T., Urbach, J. M., Miyata, S., Lee, D. G., Drenkard, E., Wu, G., Villanueva, J., Wei, T. and Ausubel, F. M. (2006). An ordered, nonredundant library of Pseudomonas aeruginosa strain PA14 transposon insertion mutants. Proc Natl Acad Sci U S A 103(8): 2833-2838.

16. Price, M. N., Wetmore, K. M., Waters, R. J., Callaghan, M., Ray, J., Liu, H., Kuehl, J. V., Melnyk, R. A., Lamson, J. S., Suh, Y., Carlson, H. K., Esquivel, Z., Sadeeshkumar, H., Chakraborty, R., Zane, G. M., Rubin, B. E., Wall, J. D., Visel, A., Bristow, J., Blow, M. J., Arkin, A. P. and Deutschbauer, A. M. (2018). Mutant phenotypes for thousands of bacterial genes of unknown function. Nature 557(7706): 503-509.

17. Veeranagouda, Y. and Didier, M. (2017). Transposon Insertion Site Sequencing (TIS-Seq): An Efficient and High-Throughput Method for Determining Transposon Insertion Site(s) and Their Relative Abundances in a PiggyBac Transposon Mutant Pool by Next-Generation Sequencing. Curr Protoc Mol Biol 120: 2135 21-21 3511.

18. Wei, L., Qiao, H., Sit, B., Yin, K., Yang, G., Ma, R., Ma, J., Yang, C., Yao, J., Ma, Y., Xiao, J., Liu, X., Zhang, Y., Waldor, M. K. and Wang, Q. (2019). A Bacterial Pathogen Senses Host Mannose to Coordinate Virulence. iScience 20: 310-323.

19. Wei, L., Wu, Y., Yang, G., Xu, R., Liu, X., Liu, Q., Zhang, Y., Ma, Y. and Wang, Q. (2019). Genome-Wide Identification of Fitness Factors in Seawater for Edwardsiella piscicida. Appl Environ Microbiol 85(10): e00233-19.

20. Yamaichi, Y. and Dorr, T. (2017). Transposon Insertion Site Sequencing for Synthetic Lethal Screening. Methods Mol Biol 1624: 39-49.

21. Zheng, J., Shin, O. S., Cameron, D. E. and Mekalanos, J. J. (2010). Quorum sensing and a global regulator TsrA control expression of type VI secretion and virulence in Vibrio cholerae. Proc Natl Acad Sci U S A 107(49): 21128-21133. 